\title{
Long-term results of arterial counterpulsation in acute severe cardiac failure complicating myocardial infarction
}

\author{
David W. Baron and Michael F. O'Rourke \\ From the Cardiovascular Unit, St. Vincent's Hospital, Sydney, and Department of Medicine, University of \\ New South Wales, Australia
}

Thirty patients were discharged from hospital after treatment with arterial counterpulsation for acute severe heart failure complicating myocardial infarction. Seventeen patients had been in cardiogenic shock-13 with power failure alone, and 4 with a mechanical complication which required corrective surgery. Thirteen patients were in impending or 'preshock'. The follow-up period after infarction averaged 13.1 months. Results were good in 'preshock' patients, and in shocked patients with a surgically correctable mechanical complication. Results were poor in shocked patients with power failure alone. Counterpulsation has an important supportive role in the treatment of complicated myocardial infarction, provided that intervention is prompt and mechanical complications, if present, are corrected early.

With ventricular fibrillation virtually eliminated as a cause of death in hospital after myocardial infarction, attention has focused on methods for treating cardiac failure which is now responsible for most hospital deaths and most late disability after infarction. The most promising new advance in this area is the counterpulsation system of ventricular assistance, which has been used effectively in treating cardiogenic shock, severe heart failure, and recurrent pain after infarction. Early results of such treatment have been reported from the Massachusetts General Hospital (Leinbach et al., 1973; Sanders et al., 1972) and other centres (Miller et al., 1974; Mueller et al., 1971; Scheidt et al., 1973). Our own experience with arterial counterpulsation began in 1971 (O'Rourke and Chang, 1974; O'Rourke et al., 1975). We report here long-term results of the first 30 patients who left hospital after treatment with arterial counterpulsation for acute severe heart failure complicating myocardial infarction.

\section{Patients}

In the 38-month period to 31 December 1974, 210 patients were referred for consideration of arterial

Received 23 September 1975. counterpulsation. Of these, 62 with acute severe heart failure complicating myocardial infarction underwent counterpulsation. Thirty patients survived and were discharged from hospital. Follow-up was conducted in March 1975 and all patients were accounted for. All but 2 surviving patients were interviewed personally, and detailed information for these 2 (who lived outside Sydney) was obtained from the attending physician.

The patients had been divided into two groups-shock and 'preshock'. The definition of shock was a modification (O'Rourke et al., 1975) of that proposed by the U.S. Myocardial Infarction Research Unit Program. 'Preshock' (O'Rourke and Chang, 1974) was a term applied to patients with acute severe refractory cardiac failure, accompanied by recurrent pain, recurrent ventricular arrhythmias or conduction disturbances, and who were deteriorating despite conventional medical therapy. Peel et al. (1962) and Norris et al. (1969) prognostic indices had predicted hospital mortality rates $>90$ per cent and $>55$ per cent, respectively, in the shock and 'preshock' groups. There were 17 hospital survivors in the shock group (of 46), and 13 hospital survivors in the 'preshock' group (of 16). The 17 survivors of cardiogenic shock were further divided into a subgroup of 13 with power failure alone causing shock, and a subgroup of 4 who survived correction of a mechanical complication which contributed to the shock state. These comprised one patient each with ventricular septal defect, haemopericardium with subacute heart rupture, haemopericardium from haemorrhagic infarct, and left ventricular aneurysm. 


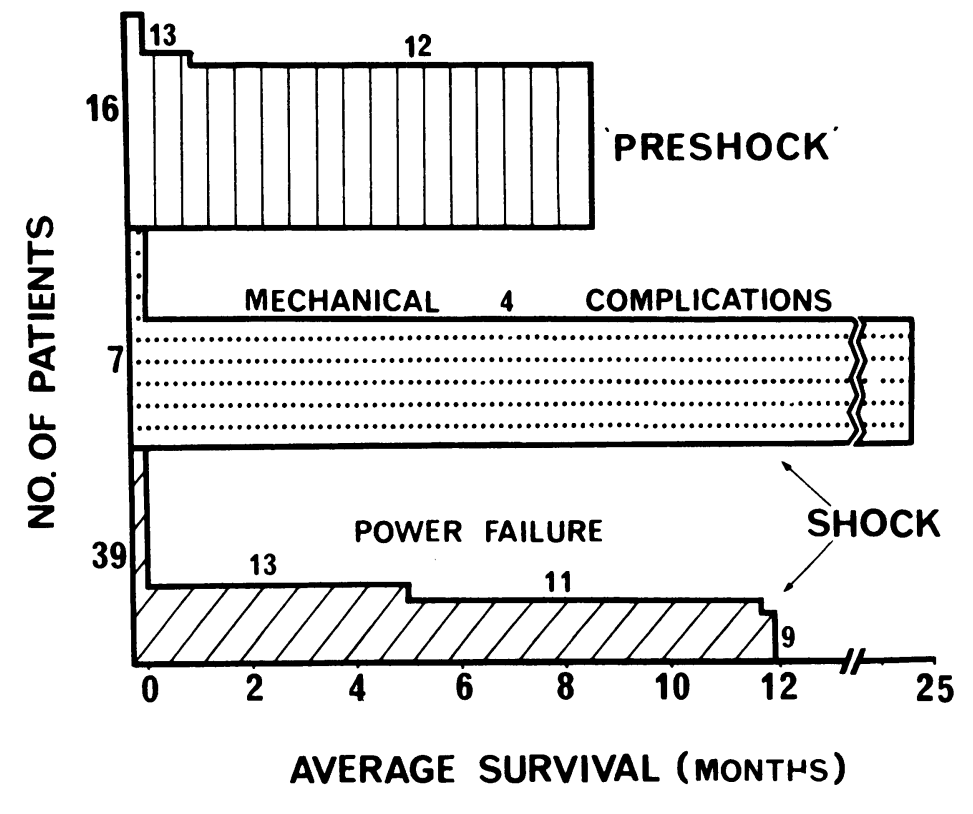

FIG. 1 Survival rates in patients treated with arterial counterpulsation for acute myocardial infarction: there were 30 hospital survivors, comprising 13 of 16 with 'pre-shock', 4 of 7 with shock caused by mechanical complications, and 13 of 39 with shock caused by pure power failure.

\section{Results}

Overall mortality rates are shown in Fig. 1. For shocked patients, results were best where mechanical complications were present. Of the 7 who underwent corrective surgery, 4 left hospital and there were no subsequent deaths on average followup of 24.5 months. Of the 39 shocked patients, without mechanical complications, there were 13 hospital survivors and 4 late deaths on average follow-up of 11.9 months. Sixteen patients were treated in hospital for 'preshock', with 13 hospital survivors, and one late death on average follow-up of 8.6 months. This patient died suddenly during uncomplicated convalescence, with evidence of acute recent coronary thrombosis at necropsy. The 4 patients who died after treatment for cardiogenic shock died in severe cardiac failure, without definite evidence of fresh reinfarction.

Quality of life after discharge from hospital was assessed according to functional activity. Each patient completed a detailed questionnaire (evolved in liaison with the National Heart Foundation N.S.W. Rehabilitation Unit), aimed at assessing symptoms, physical activity, and working ability. This was followed by personal interview of the patient, physical examination, chest $x$-ray examination, and resting electrocardiogram. Patients were classed as disabled, or as having returned to fulltime or part-time (approximately $50 \%$ of the time) activities.

Again, 'preshock' patients gave encouraging results (Fig. 2). There was one death from fresh reinfarction. Two patients were disabled: one by low output failure, and one (though physically well) by cardiac neurosis. Six had returned to full-time previous activities and another 4 were expected to do so after further convalescence, giving an 83 per cent return to work for 'preshock' survivors. The 4 patients with shock and mechanical complications stand out. All 4 had returned to full-time previous activities and required minimal treatment. One of these patients held two jobs concurrently and was leading a more active life than previously. Results with shock from power failure alone were disappointing. Four patients had died after an average survival of 9 months (range 5 to 14 months), and these had all previously been disabled. Two survivors were disabled, both by low output failure, and these required maximal treatment. Five had returned to part-time activities, and only 2 to fulltime work. 


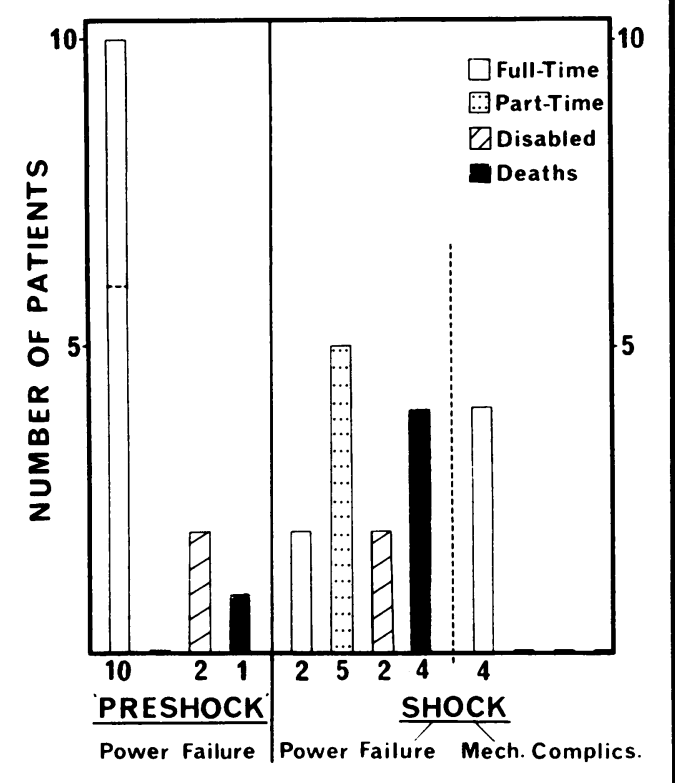

FIG. 2 Functional status of the 30 hospital survivors.

The experience with coronary artery bypass grafting in pure power failure after infarction is uncertain, 8 patients being treated with bypass grafting alone. Six patients were in cardiogenic shock, and 2 in 'preshock' with 3 hospital survivors and 1 death on follow-up. While revascularization surgery did not appear to benefit either in the short or long term, it is acknowledged that this is contrary to much of the current experience elsewhere (Miller et al., 1974; Sanders et al., 1972).

No long-term complications attributable to counterpulsation or surgery were found on followup. In particular there were no peripheral vascular complications attributable to the intra-aortic balloon.

\section{Discussion}

Of the 39 patients with cardiogenic shock as a result of power failure alone, only one-third left hospital and half of these were subsequently disabled by cardiac failure. Only $2(5 \%)$ returned to full-time work. These results are disappointing though it would be unfair to suggest that counterpulsation is not warranted in this condition. Many of the patients in this group had been in shock for over 8 hours before counterpulsation was started and many were in established acute renal failure. It is now clear from experimental studies and from our results in impending or 'preshock' that to be most effective, counterpulsation must be initiated early. Our interpretation of results to date is that counterpulsation is warranted in patients with cardiogenic shock from pure power failure, provided that past health has been reasonably good and provided that shock has not been present for more than 8 hours. Our approach to aortocoronary bypass surgery in association with counterpulsation is currently under review. Revascularization surgery was performed on 6 of the 39 patients without results being demonstrably different from the group as a whole. More encouraging results have been reported from Boston (Miller et al., 1974; Sanders et al., 1972).

In contrast to the rather gloomy results in established cardiogenic shock resulting from power failure alone, results in patients with mechanical complications of infarction have been encouraging. It is clear that a high index of suspicion must be held for the mechanical complications of infarctionruptured septum, ruptured papillary muscle, ruptured free wall with haemopericardium, or haemopericardium from haemorrhagic infarctand that counterpulsation combined with appropriate corrective surgery provides every prospect for an excellent long-term result in such patients, again provided that intervention is prompt.

Results of counterpulsation in patients with massive infarction and impending or 'preshock' have been very good in both the short and long term. It is true that this condition cannot be defined with precision and that the progression to shock cannot be predicted with certainty. However, the patients as a group had a very poor prognosis for survival in hospital as gauged by Norris et al. (1969) and Peel et al. (1962) indices. Hospital death rate in this group $(19 \%)$ was similar to the overall average for myocardial infarction treated in Australian coronary care wards (McLean, Penington, and Sloman, 1973). Long-term results were also good with only 1 of 13 patients being disabled by cardiac failure and with 10 of 13 patients returning to previous activities, and without any short or long-term complications of treatment.

We believe that the long-term results presented here justify early aggressive treatment of patients with severe heart failure complicating myocardial infarction. Good results are to be expected when intervention is early, and when mechanical complications, if present, are corrected early. Results are likely to be poor if mechanical assistance is delayed until after shock has been established for many hours. 


\section{References}

I.einbach, R. C., Gold, H. K., Dinsmore, R. E., Mundth, E. D., Buckley, M. J., Austin, W. G., and Sanders, C. A. (1973). The role of angiography in cardiogenic shock. Circulation, 48, Suppl. 3, 95.

McLean, K. H., Penington, C., and Sloman, J. G. (1973). The Australian coronary care unit review, 1970. Medical fournal of Australia, 1, 753.

Miller, M. G., Weintraub, R. M., Hedley-Whyte, J., Restall, D. S., and Alexander, M. (1974). Surgery for cardiogenic shock. Lancet, 2, 1342.

Mueller, H., Ayres, S. M., Conklin, E. F., Giannelli, S., Jr., Mazzara, J. T., Grace, W. T., and Nealon, T. F., Jr. (1971). The effects of intra-aortic counterpulsation on cardiac performance and metabolism in shock associated with acute myocardial infarction. Fournal of Clinical Investigation, 50, 1885.

Norris, R. M., Brandt, P. W. T., Caughey, D. E., Lee, A. J., and Scott, P. J. (1969). A new coronary prognostic index. Lancet, 1, 274.

O'Rourke, M. F., and Chang, V. P. (1974). The 'pre-shock' stage of massive myocardial infarction. Results of treatment with arterial counterpulsation. Medical fournal of Australia, 2, 841.

O'Rourke, M. F., Chang, V. P., Windsor, H. M., Shanahan,
M. X., Hickie, J. B., Morgan, J. J., Gunning, J. F., Seldon, A. W., Hall, G. V., Michell, G., Goldfarb, D., and Harrison, D. G. (1975). Acute severe cardiac failure complicating myocardial infarction: experience with 100 patients referred for consideration of mechanical left ventricular assistance. British Heart fournal, 37, 169.

Peel, A. A. F., Semple, T., Wang, I., Lancaster, W. M., and Dall, J. L. G. (1962). A coronary prognostic index for grading the severity of infarction. British Heart fournal, 24, 745.

Sanders, C. A., Buckley, M. J., Leinbach, R. C., Mundth, E. D., and Austin, W. G. (1972). Mechanical circulatory assistance: current status and experience with combining circulatory assistance, emergency coronary angiography and acute myocardial revascularisation. Circulation, 45, 1292.

Scheidt, S., Wilner, G., Mueller, H., Summers, D., Lesch, M., Wolfe, G., Krakauer, J., Rubenfire, M., Fleming, P., Noon, G., Oldbam, N., Killip, T., and Kantrowitz, A. (1973). Intra-aortic balloon counterpulsation in cardiogenic shock. New Enyland fournal of Medicine, 288, 979.

Requests for reprints to Dr. Michael F. O'Rourke, Medical Professorial Unit, St. Vincent's Hospital, Darlinghurst, New South Wales 2010, Australia. 